\title{
Arduino ve Wifi Temelli Çok Sensörlü Robot Tasarımı ve Denetimi
}

\author{
Abdulkadir KARACI ${ }^{1}$, Mustafa ERDEMIR ${ }^{2}$ \\ ${ }^{1}$ Mühendislik ve Mimarlık Fakültesi Bilgisayar Mühendisliği Bölümü, Kastamonu Üniversitesi, Kastamonu, Türkiye \\ ${ }^{2}$ Eğitim Fakültesi Fen Bilgisi Eğitimi Bölümü, Kastamonu Üniversitesi, Kastamonu, Türkiye \\ akaraci@kastamonu.edu.tr, merdemir@kastamonu.edu.tr \\ (Geliş/Received:20.04.2017; Kabul/Accepted:13.08.2017) \\ DOI: $10.17671 /$ gazibtd.307271
}

\begin{abstract}
$\ddot{O}_{z}$ et- Bu çalışmada arduino mikro denetleyici kartı kullanılarak çok sensörlü ve düşük maliyetli gezgin hizmet robotu geliştirilmiştir. Robotu geliştirmedeki amaç insanın giremeyeceği yerlerdeki gaz, sıcaklık ve nem ölçümlerini gerçekleştirmektir. Böylece gaz kaynaklı insan ölümlerinin önüne geçilebilecektir. Robotun geliştirilmesinde; arduino mega kontrol kartı, ultrasonik mesafe sensörü, servo motor, motor shield, wifi modül, sıcaklık ve nem sensörü, metan gaz sensörü, motor shield ve de motor kullanılmıştır. Bu araçlarla birlikte engel algılama ve yön bulma yazılımı geliştirilerek genel çalışma diyagramı oluşturulmuştur. Robot, mesafe sensörleri yardımıyla kapalı yerlere girebilmekte, uygun açıklığı tespit ederek çıkış yolunu bulabilmekte ve üzerinde bulunan sensörler yardımıyla elde edilen verileri wifi aracılığıly bilgisayar ortamına aktarılabilmektedir. Bu veriler web sayfasından takip edilebilmektedir. Robot üzerine kullanım amaçlarına uygun olarak daha fazla sensör yerleştirilebilmektedir. Bu çalışmada bu robotun elektronik ve yazılımsal yönü ayrıntılı olarak incelenmektedir. Yapılan testler sonucunda robotun, sensörlerden aldığı bilgileri istenen zaman aralığında başarılı bir şekilde web modülüne gönderdiği ve kapalı bir alanda kaldığında çıkış yolunu 3-4 denemede bulduğu görülmüştür. Geliştirilen robot, insanların girmekte zorlandığı ve canlılar için tehlikeli olan yerlerdeki gaz, nem ve sıcaklıkla ilgili bilgilere ulaşmakta kullanılabilir. Ayrıca üzerine kamera monte edilerek manuel şekilde uzaktan kontrol edilebilir ve amaca uygun farklı sensörler kullanılarak istenilen veriler elde edilebilir.
\end{abstract}

Anahtar Kelimeler - arduino, gezgin hizmet robotu, sensör

\section{Arduino and Wi-Fi Based Multisensor Robot Design and Control}

\begin{abstract}
In this study, a multi-sensor, low-cost mobile service robot was developed using the arduino microcontroller card. The goal in developing the robot is to carry out measurements of gas, temperature and humidity in places where the human can not enter. Thus, gas-induced human deaths can be avoided. In the development of the robot, arduino mega control card, ultrasonic distance sensor, servo motor, motor shield, wifi module, temperature and humidity sensor, methane gas sensor, motor shield and dc motor are used. Along with these tools, obstacle detection and navigation software was developed and a general working diagram was created. The robot can enter closed places with the help of distance sensors, find the exit way by detecting the appropriate openness and the data obtained with the help of the sensors located on it can be transferred to the computer environment via wifi. This data can be viewed on the web page. More sensors can be placed on the robot for their intended use. In this study, electronic and software aspects of this robot are examined in detail. As a result of the tests, the robot successfully sent the information it received from the sensors to the web module at the desired time interval and found that the exit path was found in 3-4 tests when a closed area was left. The developed robot can be used to get information about gas, humidity and temperature in places where people are difficult to enter and dangerous for living things. In addition, by mounting the camera on it, it can be remotely controlled manually and the desired data can be obtained by using different sensors suitable for this purpose.
\end{abstract}

Keywords - arduino, mobile service robot, sensor 


\section{GİRIŞ (INTRODUCTION)}

Geçtiğimiz on yılda, mobil robotlar askeri ve endüstriyel ortamdan çekilerek hastaneler, okullar ve sıradan evler gibi sivil ve kişisel alanlara girmektedir [1]. Robotlar, özellikle tekrar eden görevleri yerine getirmede insanların yerini almaktadır. Robotik genel olarak, endüstriyel ve servis robotları olmak üzere iki alana ayrılabilir. Uluslararas1 Robotik Federasyonu hizmet robotunu, insanların refahı için faydalı olan hizmetleri gerçekleştiren, kısmen veya tamamen bağımsız olarak çalışan bir robot olarak tanımlamaktadır [2]. Yapılacak işin farklı yerlerde gerçekleştirilmesi robotların gezgin olmasını gerektirmektedir. $\mathrm{Bu}$ tür görevlere yönelik olarak tasarlanmış gezgin robotlar üç kısımdan oluşur. İlk kısım hareketi sağlayan mekanik, ikinci kısım kontrol birimleri ve algılayıcılar vasıtasıyla algılanan verilerin işlenmesini sağlayan donanım, üçüncü kısım ise hareket kontrolünü ve karar almayı sağlayan yazılımdır [3] Arduino; birçok kişi tarafından yaygın olarak kullanılan bir mikro denetleyici karttır. Esnek, kullanımı kolay ve eksiksiz bir donanım ve yazılım ortamı sunar. $\mathrm{C} / \mathrm{C}++$ temelli Arduino dili kullanılarak programlanabilmektedir. Ayrıca Arduino'nun Windows, OS X ve Linux sistemleri için entegre geliştirme ortamı (IDE) mevcuttur ve bu ortamda çok sayıda öğretici ve kapsamlı belge bulunmaktadır [4].

$\mathrm{Bu}$ çalışmadaki amaç, insanın giremeyeceği yerlerdeki gaz, sıcaklık ve nem ölçümlerini gerçekleştiren, bu ölçümleri web sayfasına ileten, engelleri tespit ederek engellere çarpmayan, bir yerde kapalı kalırsa ve uygun bir açıklık varsa o açıklı̆̆ı tespit ederek çıkış yolunu bulabilen bir gezgin hizmet robotu geliştirmektir. $\mathrm{Bu}$ amaçla arduino mikro denetleyici kartı kullanarak çok sensörlü ve düşük maliyetli gezgin bir hizmet robotu geliştirilmiş ve değerlendirilmiştir. Bu robot vasıtasıyla gaz kaynaklı insan ölümlerinin önüne geçilebilecektir. İstenirse robota farklı sensörler eklenerek uzaktan izlenebilecektir.

\section{2. ÖNCEKİ ÇALIŞMALAR (PREVIOUS STUDIES)}

Dalkılıç ve Özcanhan (2016) arduino uno kullanarak mobil araç geliştirmişlerdir. Bu araç, Android işletim sistemine sahip bir akıllı telefon uygulaması aracilığıla bluetooth üzerinden uzaktan kontrol edilebilmektedir [5] Güngör (2015) Arduino tipi mikrodenetleyici ve GSM modülleri ile kaçak elektrik kullanımlarının takibini yapmıştır. Yapılan diğer çalışmalardan farklı olarak GSM haberleşmesini kullanmıştır [6]. Lubbe ve Kluge (2008) kablosuz ağ üzerinden uzaktan kontrol edilebilen bir prototip araba geliştirmişlerdir. Geliştirdikleri araba üzerine kamera entegre ederek buradan görüntü transferini gerçekleş̧irmişlerdir [7]. Bazı insanlar yoğun çalışma temposu nedeniyle araçlarını bakıma götürememektedir. Thomas ve arkadaşları (2016) bu insanlar için yardımcı bir sistem geliştirmişlerdir. Geliştirilen sistemde yakıt seviyesi, motor sıcaklığı ve akü gerilimi gibi veriler sensörler vasitasıyla okunarak arduino karta iletilmektedir. Arduino karta iletilen bu veriler anlaml bilgi haline getirilerek bluetooth vasıtasıyla android üzerinde geliştirilmiş bir uygulamaya gönderilmektedir. Ayrıca sistem alkol sensörü vasıtasıyla sürücünün alkol düzeyini de ölçerek sürücüyü uyarmaktadır [8]. Araç güvenlik sistemlerini ucuza imal etmek önemlidir. Sinha ve arkadaşları (2016) her araca monte edilebilen bir araç güvenlik sistemi geliştirmişlerdir. Sistem bir butona basılarak aktif edilmekte ve araç çalındığında GSM modül vasıtasıyla alarm gönderilmekte ve GPS vasitasıyla da aracin konumu bildirilmektedir [9]. Arabalarda hiz kontrol sistemi ya hızını korur ya da önünde bir araç varsa hızını azaltır. Ancak bazı durumlarda araç hızı sıfır olabilir. Bu durumu engellemek için Vaishnavi ve arkadaşları (2016) aracın boş olan şeride geçmesini sağlamak için bir sistem geliştirmiş̧lerdir. $\mathrm{Bu}$ sistemde aracın 4 ana bölümüne ultrasonik sensör eklenmiş ve bu sensörlerden gelen bilgiler bir algoritma ile değerlendirilerek motorlar buna göre yönlendirilmiştir [10]. Arduino mega kartı kendini dengede tutan iki tekerlekli robotlarda da kullanılmaktadır. Juang ve Lum (2013) 2 DC motor, Arduino mega, tek eksen jiroskop ve 2 eksen ivme ölçer kullanarak kendini dengede tutan düşük maliyetli bir robot geliştirmişledir [1]. Yavuz ve arkadaşları da iki tekerlekli kendini dengeleyen robot geliştirmişlerdir. Robotun geliştirilmesinde, arduino uno, geri besleme verileri, ivmeölçer ve gyro sensör kullanmışlardır. Ayrıca tasarladıkları robot üzerinde üç farklı kontrol algoritması (PI kontrol, PD kontrol, PID kontrol) uygulamış ve bu kontrol algoritmalarını test ederek hız, doğruluk ve kararlılık gibi özellikleri karşılaştırmışlardır [11]. Yalman ve Haşıloğlu (2015) hastanelerde eşzamanlı ilaç dağıtımı yapan hemşire/hemşir robot modeli geliştirmişlerdir [12].

\section{YÖNTEM (METHOD)}

Robotun geliştirilme aşaması donanım ve yazılım olmak üzere iki kısımda incelenmektedir. Donanım, mekanik tasarım ve elektronik tasarım olarak iki farklı başlık altında sunulmaktadır. Elektronik tasarımın gerçekleştirilmesinde; arduino mega kontrol kartı, ultrasonik mesafe sensörü, servo motor, motor shield, wifi modülü, sıcaklık ve nem sensörü, metan gaz sensörü, motor shield ve dc motor kullanılarak genel diyagram oluşturulmuştur. Mekanik tasarım; robotun mekanik gövdesinin ve hareket kabiliyetinin oluşturulması üzerine yapılan çalışmalardan oluşmaktadır. Yazılım kısmı iki farklı görevi üstelenmektedir. Birincisi engeli algılayıp uygun yönü bulma, ikincisi ise $1 S 1$, nem ve gaz sensörlerinden elde edilen verilerin wifi modül vasıtasıyla web modülüne gönderilmesidir.

\subsection{Gezgin Hizmet Robotun Genel Tasarımı (General Design of Mobil Service Robot)}

Geliştirilen robotun öncelikle mekanik kısmı tamamlanmıștır. Daha sonra bu mekanik kısım üzerine mikro denetleyici ve sensörler yerleştirilmiştir. Son olarak amaçlanan fonksiyonları gerçekleştirmesi için 
programlanması yapılmış ve test edilmiştir. Tasarlanan robotun basitleştirilmiş genel diyagramı şekil 1'de gösterilmektedir.

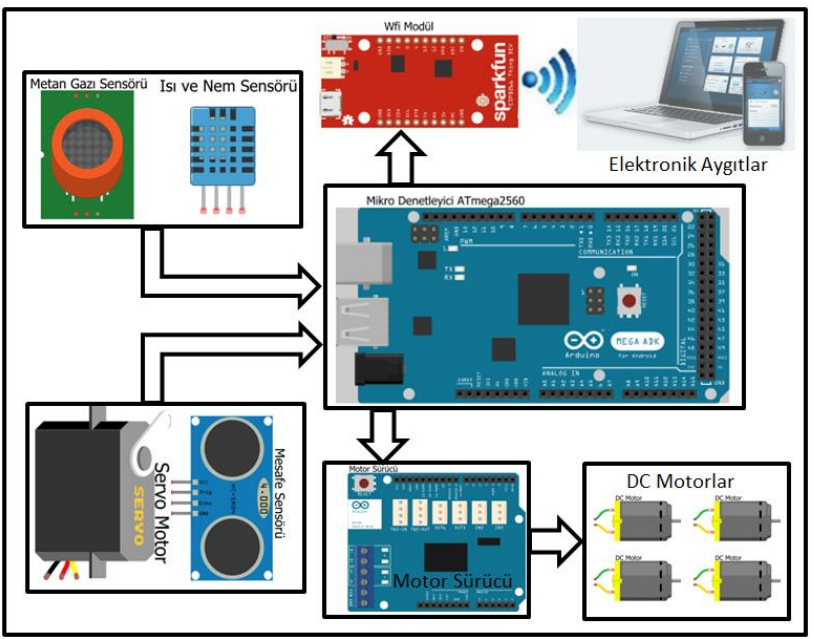

Şekil 1. Robotun basitleştirilmiş genel diyagramı (Simplified general diagram of the robot)

Şekil 1'de de görüldüğü gibi metan gaz sensörü ve 1s1nem sensörlerinden elde edilen bilgiler wifi modülü vasıtasıyla web modülüne gönderilmektedir. Bu ölçümler interneti olan herhangi bir elektronik aygıt vasıtasıyla izlenebilmektedir. Robotun engele çarpmaması için mesafe sensöründen gelen bilgiler mikro denetleyicide değerlendirilerek ilgili komut, motor sürücü üzerinden dc motorlara iletilmektedir. Robot kapalı bir alanda kaldığında çıkmak için bir açıklık aramaktadır. Bunu gerçekleştirebilmek için, servo motor üzerine monte edilmiş mesafe sensörü vasıtasıyla 180 derecelik bir alan taranmaktadır. Ayrıca robotun arka kısmına sabitlenmiş olan mesafe sensöründen gelen bilgi de değerlendirilmektedir. Robot en uzak mesafenin bulunduğu yöne dönmekte ve bu yönde hareketini sürdürmektedir.

\subsection{Mekanik Tasarım(Mechanical Design)}

Bir robot tasarlanmaya karar verildiğinde karşılaşılan en temel problem robotun mekanik tasarımıdır. $\mathrm{Bu}$ problem imalat ile rahatça çözülebilse de maliyet açısından çoğu durum için uygun değildir. Bu probleme en temel çözüm hazır modüller yardımıyla bir robot oluşturmak veya daha önceden oluşturulmuş mekanik dizgelerin omurgalarından yararlanmaktır [12]. Bu çalışma kapsamında hazır modül kullanılmıştır. Kullanılan hazır modül 4WD Çok Amaçlı Mobil Robot Platform modülüdür.

Robotun düzlemsel hareketi 4 adet 6v, 160mA, $250 \mathrm{rpm}$ plastik redüktörlü DC motor ile sağlanmaktadır. Motorlara, 1 adet 7.4 V, 1350mAh 25C Lityum Polimer pil ile güç sağlanmaktadır. Kullanılan pil sürekli olarak 33,75 A akım sağlamaktadır. Şekil 2'de sensörler vasitasıyla gaz, 1S1 ve nem ölçümlerini yapıp wifi üzerinden web tabanlı sisteme gönderen robotun mekanik tasarımı gösterilmektedir.

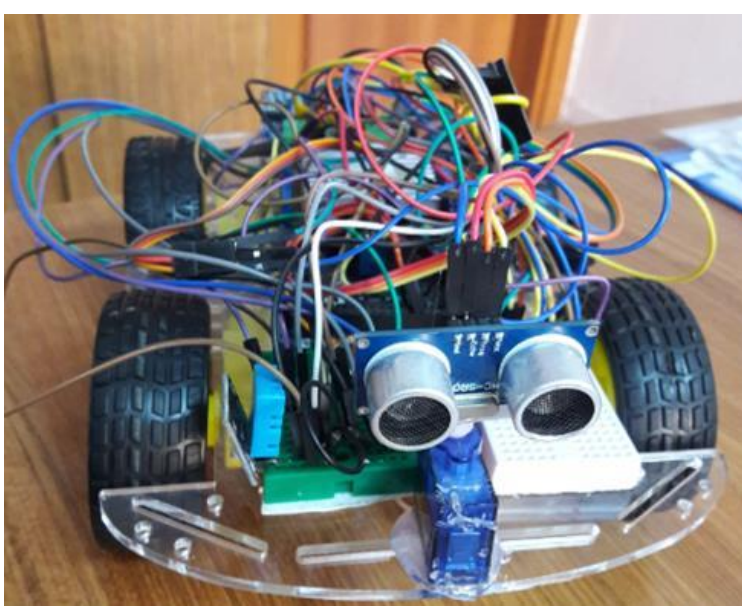

Şekil 2. Çok sensörlü robotun mekanik tasarımı (Mechanical design of multi-sensor robot)

\subsection{Elektronik Tasarım(Electronic Design)}

$\mathrm{Bu}$ bölümde robotta kullanılan elektronik modüller, özellikleri ve robotta üstelendiği görevleri açıklanmaktadır. Robotun elektronik tasarımında Arduino Mega kontrol kartı, motor sürücü, 2 adet ultrasonik mesafe sensörü, 1 adet servo motor, ESP8266 wifi modülü, DHT11 sıcaklık ve nem sensörü ve MQ-4 metan gazı sensörü kullanılmıştır. Robota ait elektronik tasarım şekil 3'de gösterilmektedir.

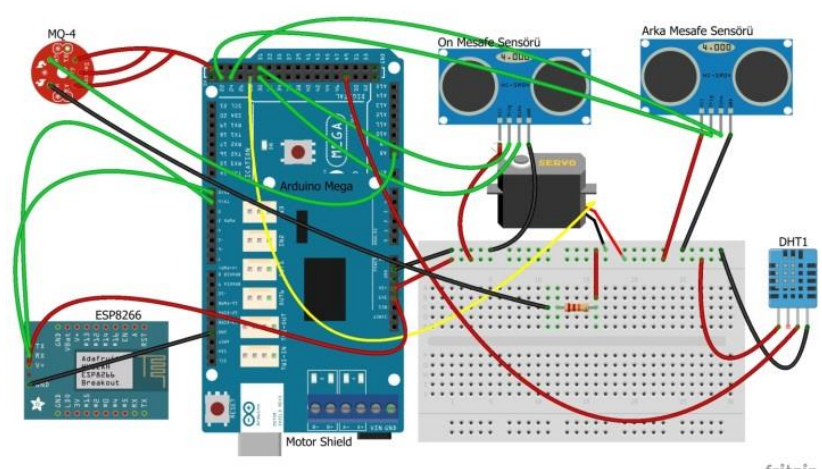

Şekil 3. Robotun elektronik tasarımı (Electronic design of robot)

Arduino Mega Kontrol Kartı: Arduino, processing /Wiring dilini kullanarak çevre elemanları ile temel çıkış uygulamalarını gerçekleştiren açık kaynaklı fiziksel programlama platformudur [6]. Arduino kart ucuzdur ve ihtiyaca uygun olarak satın alınan shield denilen çevre birimleri vasıtasıyla genişletilebilir. Arduino çok ucuz ve kolay erişilebilir bir kart olmasına karşın çok işlevseldir. Akademik ve öğrenci projeleri için ideal çözümler sağlar [1]. Bu nedenle bu çalışmada Arduino Mega kontrol kartı kullanılmıştır. Bu kart vasıtasıyla sensörlerden gelen bilgiler gerek wifi üzerinden web modülüne, gerekse motorlara gönderilmektedir.

Arduino Mega, ATmega2560 işlemcisi temelli bir mikroişlemci kartıdır. Arduino mega'da 54 adet dijital giriş/çıkış pini bulunmaktadır ve bunların 14'ü PWM çıkışı olarak kullanılabilmektedir. Onaltı adet analog giriş 
pini ve 4 adet donanım seri portu (UART) bulunmaktadır. $16 \mathrm{MHz}$ kristal osilatörü, USB bağlantısı, bir güç girişi, bir ICSP başlığı ve reset butonu kart üzerinde mevcuttur. Çalışma gerilimi olarak DC 7 12V ihtiyaç duymaktadır. $\mathrm{Bu}$ kart mikro denetleyicinin ihtiyaç duyduğu her şeyi üzerinde barındırır. USB kablo ile bilgisayara kolayca bağlanabilir. Ayrıca istenirse AC-DC adaptör veya pil vasıtasıyla da başlatılabilir [13].

$\mathrm{Bu}$ çalışmada başlangıçta arduino uno kullanılmıştır. Ancak kullanılan motor ve sensör adedi arttıkça pinler yetersiz kalmıştır. Ayrıca kullanılan shield'ların kullandıkları pinlerde de çakışma olmuştur. $\mathrm{Bu}$ sebeplerden dolayı daha fazla dijital ve analog pine sahip olan Arduino Mega kontrol kartı seçilmiştir.

Ultrasonik Mesafe Sensörü: Ultrasonik sensörler 1980'li yılların ortalarından itibaren otonom mobil robotların engellerden kaçınmaları ve harita oluşturmada kullanılmaktadır. Ultrasonik sensör üzerindeki verici tarafından ses dalgası yayılır. Bu ses dalgası engele çarpıp yansır. Yansıyan bu dalganın ultrasonik sensör üzerindeki alıcı tarafından algılanması için geçen süre (uçuş süresi) kullanılarak mesafe ölçülür [14].

$\mathrm{Bu}$ çalışmada mesafe ölçmek için 2 adet HC-SR04 ultrasonik mesafe sensörü kullanılmıştır. Sensör $2 \mathrm{~cm}$ 'den $400 \mathrm{~cm}$ 'ye kadar $3 \mathrm{~mm}$ hassasiyetle ölçüm yapabilmektedir. İki adet sensörden bir tanesi robotun ön tarafına servo motor üzerine monte edilmiştir. Servo motor 180 derece sağa sola dönebilmektedir. Mesafe sensörü bu sayede daha fazla alanı taradığından dolayı gidilmesi gereken yöne daha doğru karar verilebilmektedir. Çünkü otomatik modda robot kendisi hareket etmektedir ve algoritmik olarak en uzak mesafeye gitmeye çalışmaktadır. Bu sayede herhangi bir yerde sıkıştığı zaman sıkıştığı yerden en uygun çıkışı bularak çıkabilmektedir. Diğer sensör robotun arkasına monte edilmiştir. Bu sayede robot arkasındaki engelleri de tespit edebilmektedir. Ayrıca robot bir yerde sıkıştığında eğer uygun çıkış arkada ise bu sensör vasıtasıyla bunu algılamakta ve 180 derece dönerek o bölgeden çıkabilmektedir.

Servo Motor: Servo motor, sistemin yukar1-aşağı veya sağa-sola kontrol edilmesi gereken birçok uygulamada kullanılan geri bildirimli DC tipi motorlardan biridir. Servolar, robotikte son derece yararlıdır. Servo motor, düşük devirde yüksek tork sağlar. Bir servo motordan çıkan üç kablo vardır. Bunlardan ikisi güç ve toprak, diğeri ise motora konum kontrol sinyalinin gönderildiğ çıkıştır. Servo motor bir seri darbe (pulse) ile kontrol edilir. $\mathrm{Bu}$ darbenin uzunluğu servonun alacağı pozisyonu belirler [2]. Geliştirilen robot üzerinde 1 adet Feetech FS90R sürekli dönebilen micro servo motor kullanılmıştır. $\mathrm{Bu}$ motor üzerine ultrasonik mesafe sensörü monte edilmiştir ve sensörün daha fazla alanı taraması amaçlanmıştır.
Motor Shield: Arduino Mega kartı her I/O için maksimum $40 \mathrm{~mA}$ akım sağlayabilmektedir. Ancak araç üzerinde çalışan 4 adet DC motor yaklaşık 640 mA akım çekmektedir. Bu nedenle DC motorlar doğrudan Arduino Mega kartı üzerinden beslenememektedir. Araç üzerindeki 4 adet DC Motor, Motor Shield V2.0 ile sürülmektedir. $\mathrm{Bu}$ motor shield üzerinde L298 motor sürücü entegresi vardır ve 2 kanallıdır. Robot üzerinde 4 adet DC motor kullanıldığından kanal başına 2 adet motor bağlanmıştır. $\mathrm{Bu}$ durum motor shield kanal başına $2 \mathrm{~A}$ akım sağladığ 1 için sorun teşkil etmemektedir. Motorların hız ve yönleri birbirinden bağımsız olarak kontrol edilebilmektedir. Motor sürücü, robotun istenilen yöne gitmesi veya dönmesi için bir aracı olarak kullanılmaktadır. Bu işlemin nasıl gerçekleştiği yazılım bölümünde açıklanmaktadır.

Wifi Modül: Bu modül internete bağlanarak, internete veri yüklemek ya da almak için kullanılan modüldür. Wifi modül kullanılarak wifi-yönlendiriciye bağlanılır. Böylece internete veri gönderilebilir. Wifi modülü, Arduino düğümünden web sunucularına standart HTTP protokolünü kullanarak veri aktarımı yapılmasına olanak tanır [15].

Bu çalışmada wifi modül olarak ESP 8266 modülü kullanılmıştır. $\mathrm{Bu}$ modül internete bağlanmak için en yetenekli modüllerden biridir. ESP 8266 herhangi bir mikro denetleyici veya mikroişlemciye bağlanmadan bağımsız olarak da çalışabilir. $\mathrm{Bu}$ modülün farklı versiyonları vardır. Bu çalışmada kullanılan sürüm ESP 8266-01 sürümüdür. Bu sürüm genel amaçlı giriş/çıkış portuna (GPIO) daha az ihtiyaç duyan küçük uygulamalarda yaygın olarak kullanılan ucuz bir sürümdür [16].

Modül kullanılmadan önce güncelleme işlemi gerçekleştirilmiştir. Bu işlem gerçekleştirilmeden modül çalışmamaktadır. ESP8266 hazır olduğunda kablosuz ağa bağlanır ve analog pinlere bağlı olan sensörlerden veriler okunur. Okunan bu değerler string bilgiye dönüştürülerek web üzerindeki veriler güncellenir. Bu güncelleme işlemi 5 dakikada bir gerçekleştirilmektedir. Sicaklık, nem ve metan gazı ölçüm sonuçlarını saklamak için https://thingspeak.com/ com sayfasından bir kanal açılmıştır. Bu kanala kaydedilen bilgiler IFrame olarak http://www.turkzos.com/olcum.html sayfasına çekilerek grafiksel olarak gösterilmektedir. Bu sayfa yazarlar tarafından tasarlanmıştır.

Isl ve Nem Sensörü: Isı ve nem sensörü olarak piyasada pek çok farklı tipte nem sensörü bulmak mümkündür. Ancak DHT11 sensörünün hazır kütüphanesi Arduino ortamında tanımlıdır [17]. Bu nedenle geliştirilen robotta DHT11 olarak bilinen 1sı ve nem sensörü tercih edilmiştir.

Metan Gaz Sensörü: Metan gazını ölçmek için MQ-4 metan gaz sensörü kullanılmıştır. MQ-4, 300ppm ve 10000 ppm aralığındaki metan gazı (CNG) varlığını 
algılar. Bu aralık gaz kaçaklarının algılanması için uygun bir aralıktır. Diğer MQ sensörler gibi bu sensör de çıkış olarak gazın yoğunluğuna göre analog voltaj çıkışı verir.

\subsection{Gezgin Hizmet Robotu için Gerçeklenen Yazılımlar (Software for Mobile Robot)}

Gezgin hizmet robotu için geliştirilen yazılım iki kısımda incelenebilir. Birincisi engel algılama ve yön bulma yazılımıdır. İkincisi ise sensörlerden 1s1, nem ve gaz ölçümlerinin alınarak wifi modül vasıtasıyla web modülüne gönderilmesi yazılımıdır.

\subsubsection{Engel Algılama ve Yön Bulma Yazılımı (Obstacle Detection and Navigation Software)}

Engel algılama ve yön bulma yazılımında iki adet ultrasonik mesafe sensöründen alınan veriler değerlendirilmektedir. Sensörlerden biri robotun arkasında, diğeri ise önündeki servo motor üzerinde bulunmaktadır. Ön taraftaki mesafe sensörü, servo motor vasitasıyla 180 derecelik bir alandaki mesafeyi ölçmektedir. Böylece döneceği açı ve bu açının yönü mesafe sensöründen gelen en uzak mesafeye göre tespit edilmektedir. Robotun engellere çarpmaması için durma mesafesi $10 \mathrm{~cm}$ olarak belirlenmiştir. Yani robot $10 \mathrm{~cm}$ mesafede bir engel gördüğünde durmaktadır. Daha sonra ön ve arka mesafe sensörlerinden gelen bilgileri değerlendirerek gideceği yöne karar vermektedir. Robot sola dönecekse; sağ motorlara ileri, sol motorlara geri gidecek şekilde güç verilmektedir. Sağa dönecekse bu işlem tam tersi yönde gerçekleştirilmektedir. Ayrıca tespit edilen açı kadar dönmesi için motorların dönme süreleri de önemlidir. Bu süreyi tespit etmek için robota 180 derece dönmesini sağlayacak program kodu yüklenmiş ve bir takım denemeler yapılmıştır. Bu denemeler sonucunda robotun 180 derece dönebilmesi için 2160 mili saniye(ms) güç verilmesi gerektiği tespit edilmiştir. Böylece robotun 1 derece dönmesi için güç verilme süresi $\left(\mathrm{S}_{1 \mathrm{derece}}\right)$;

$S_{1 \text { derece }}=2160 \mathrm{~ms} / 180^{\circ}=12 \mathrm{~ms}$ şeklinde hesaplanmıştır.

Robotun istenen açıda dönmesi için güç verilme süresi $\left(\mathrm{S}_{\mathrm{xderece}}\right)$ ise;

$\mathrm{S}_{\mathrm{xderece}}=\mathrm{x} .12 \mathrm{~ms}$ şeklinde hesaplanmıştır. $\mathrm{x}=$ dönme açısı.

$\mathrm{Bu}$ hesaplamalar vasitasıyla robotun istenen yöne dönmesi sağlanmıştır. Eğer en uzak mesafe arka sensörden gelmişse ön sensörden gelen veri ihmal edilerek robot $180^{\circ}$ geriye dönmektedir. Robotun engel algılama ve uygun yöne gitmesi ile ilgili videolar internet üzerinden izlenebilir $[18,19]$.

Engel algılama ve yön bulma yazılımının akış şeması şekil 4'de gösterilmektedir.

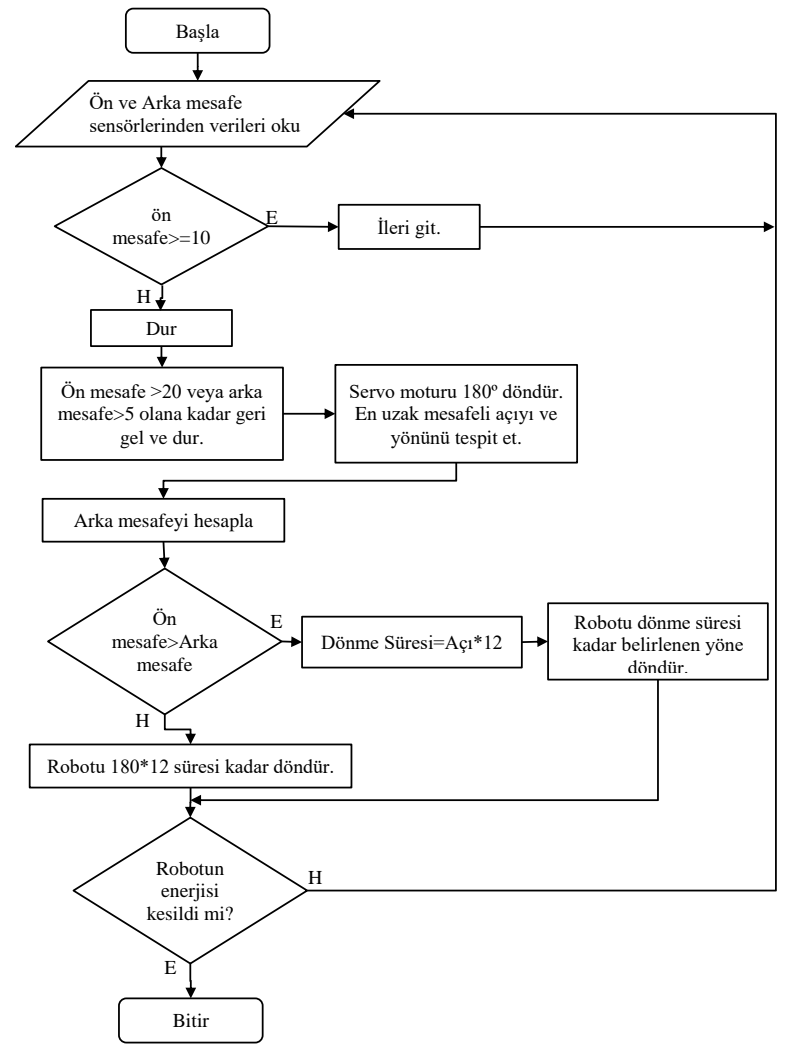

Şekil 4. Engel algılama ve yön bulma yazılımının akış şemas1

(Flow chart of obstacle detection and navigation software)

\subsubsection{Wifi Modülü İle Sensör Verilerini Gönderme Yazılımı (Software to Send Sensor Data with Wifi Module)}

Robota enerji verildiğinde wifi modülü (ESP 8266) daha önceden yazılıma yüklenilen bilgiler vasıtasıyla internete bağlanır. long zaman=millis()/1000; komutuyla robotun çalışma zamanı saniye cinsinden hesaplanır. zaman $\% 300$ işleminin sonucuna bakılarak 5 dakika olup olmadığına bakılır. Her 5 dakikada bir MQ-4 ve DHT11 sensörlerinden gelen veriler okunur. Okunan bu verileri wifi üzerinden web modülüne göndermek için aşağıdaki komut satırı vasıtasıyla sunucuya bağlanılır.

AT+CIPSTART="TCP","184.106.153.149",80

$\mathrm{Bu}$ komut satırındaki IP adresi thingspeak.com web sitesine aittir. ThingSpeak, canlı veri akışlarının bulutta toplanmasına, görselleştirilmesine ve analiz edilmesine olanak tanıyan bir IoT analiz platformudur. ThingSpeak, cihazlar tarafindan ThingSpeak'a gönderilen verilerin anında görselleştirilmesini sağlar. Bu çalışma kapsamında bu siteden kanal açılmıştır. Bu kanaldaki bilgiler IFrame vasitasıyla yazarlar tarafindan tasarlanan web sayfasina çekilmektedir. Çekilen bu ölçüm bilgileri http://www.turkzos.com/olcum.html sayfasından yayınlanmaktadır. AT + CIPSEND $=71$ komut satırıyla 71 baytlık veri ESP8266 modülüne bildirilmektedir. Modül uygunsa geriye ">” karakterini döndürmektedir. 
Yazılımda bu karakter kontrol edilerek aşağıdaki veri gönderme komutu çalıştırılmaktadır.

\section{GET /update?api_key=}

USV4JMCH7L4MD30\& field $1=192$ field $2=23 \&$ field $3=60$

Bu komuttaki field1 gaz, field2 sicaklik ve field3 ise nem değerlerini temsil etmektedir. Bu değerler yukarıdaki komut satırına sensörlerden gelen bilgilere göre program içinde dinamik olarak eklenmektedir. Veri gönderme işlemi arduino IDE ortamının seri port ekranında şekil 5 'de gösterildiği gibi takip edilebilmektedir.

\begin{tabular}{|c|c|}
\hline \multicolumn{2}{|l|}{ (6) COM10 (Arduino Mega ADK) } \\
\hline & Gönder \\
\hline \multicolumn{2}{|l|}{ AI+CWJAP="Baba1", "kar99k2005" } \\
\hline \multicolumn{2}{|l|}{ AI+CIPSTART $=" T C P ", " 184.106 .153 .149 ", 80$} \\
\hline \multicolumn{2}{|l|}{$\mathrm{AI}+\mathrm{CIPSEND}=71$} \\
\hline \multicolumn{2}{|l|}{ AT+CIPCLOSE } \\
\hline \multicolumn{2}{|l|}{ AT+CIPCLOSE } \\
\hline \multicolumn{2}{|l|}{ AT+CIPSTART="TCP", "184.106.153.149", 80} \\
\hline \multicolumn{2}{|l|}{$\mathrm{AI}+\mathrm{CIPSEND}=71$} \\
\hline \multicolumn{2}{|c|}{ GET /update?api_key=USV4 JMCH7L 4 MDF $30 \&$ field1 $=192 \&$ field $2=23 \&$ field $3=60$} \\
\hline \multicolumn{2}{|l|}{ AT+CIPSTART="TCP", "184.106.153.149", 80} \\
\hline \multicolumn{2}{|c|}{ AI +CIPSEND $=71$} \\
\hline \multicolumn{2}{|c|}{ GET /update?api_key=USV4 JMCH7L4MDF $30 \&$ field $1=196 \approx$ field $2=23 \approx$ field $3=60$} \\
\hline \multicolumn{2}{|l|}{ AT+CIPSTART="TCP", "184.106.153.149", 80} \\
\hline \multicolumn{2}{|c|}{$\mathrm{AT}+\mathrm{CIPSEND}=71$} \\
\hline \multicolumn{2}{|c|}{ GET /update?api_key=USV4 JMCH7L 4MDF $30 \approx$ field1 $=196 \approx$ field2 $=23 \approx \mathrm{field} 3=60$} \\
\hline \multicolumn{2}{|l|}{ AT+CIPSTART="TCP", "184.106.153.149", 80} \\
\hline $\mathrm{AT}+\mathrm{CIPSEND}=71$ & \\
\hline
\end{tabular}

Şekil 5. Wifi üzerinden veri gönderme işleminin seri port üzerinden izlenmesi

(Monitoring of data transmission via Wifi in serial port)

Gönderilen ölçüm verileri web modülüne kaydedilmekte ve bu veriler zamana bağlı olarak grafiksel olarak şekil 6 'daki gibi gösterilmektedir.

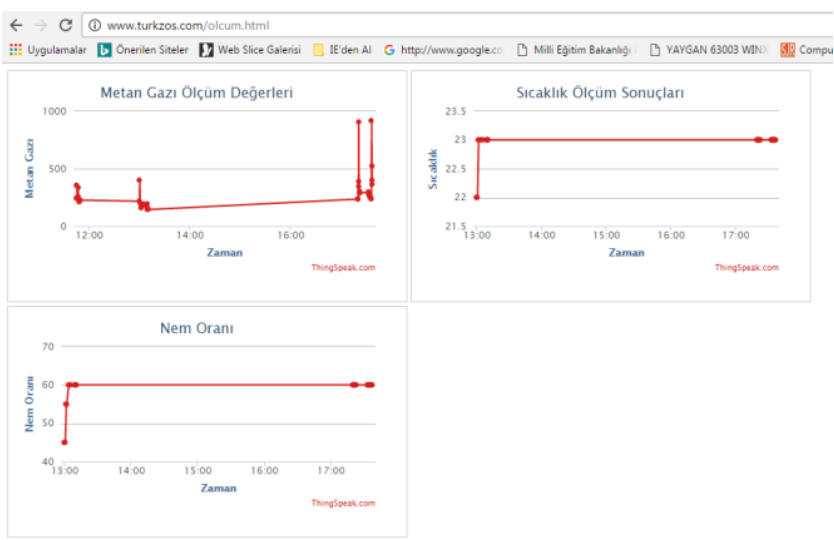

Şekil 6. Gaz, Sicaklık ve Nem değerlerinin web modülünde gösterilmesi

(Display of gas, temperature and humidity values in web module)
Gaz, sıcaklık ve nem değerlerinin web modülünde gösterilmesi ile ilgili video internet üzerinden izlenebilir [20].

\section{BULGULAR (FINDINGS)}

Geliştirilen gezgin hizmet robotu iki başlık altında değerlendirilebilir. Birincisi robotun engelleri tespit ederek gitmesi gereken uygun yönü ve açıyı tespit etmesidir. $\mathrm{Bu}$ işlemin gerçekleştirilmesindeki en büyük zorluk robotta kullanılan ultrasonik mesafe sensörünün kararlı sonuç vermemesidir. Bu nedenle robot kapalı bir alandaki açıklığı bulup çıkmak için bazen çok çaba sarf etmektedir. Bu nedenle piyasada bulunan daha kaliteli mesafe sensörlerinin kullanılması maliyeti artırmakla beraber robotun daha etkili ve kararlı çalışmasına katkı sağlayacaktır. Ayrıca ultrasonic mesafe sensörü yerine kızılötesi (IR) algılayıcı kullanılması mesafe ölçümünü ve engel algılamayı daha güvenli hale getirebilir. Zaten IR algılayıcılar uzaklık ölçmede günümüzde yaygın olarak kullanılmaktadır. IR algılayıcılar ile ölçülebilen mesafe, $10 \mathrm{~cm}$ ila $80 \mathrm{~cm}$ arasında değişebilir [3]. Robot genellikle 3-4 denemede kapalı bir alandan kolayca çıkabilmektedir. Bunun dışında 3 tarafı kapalı dar bir alana bırakıldığında bir denemede açıklığı bularak bu alandan çıkabilmektedir. Diğer bir zorluk robotun tespit edilen açıda dönmesini sağlamaktır. $\mathrm{Bu}$ işlem gerçekleştirilirken sol ve sağ taraftaki motorlar belirli bir süre ters yönde dönmektedir. Burada önemli olan bu sürenin hesaplanmasıdır. Dönme süresinin hesaplanmasında zeminin de etkisi bulunabilmektedir. $\mathrm{Bu}$ nedenle zemine göre bu parametrenin güncellenmesi gerekebilir. Ayrıca dönüş açısının doğrulanması için bir geri beslemeli kontrol döngüsü çerçevesinde sensörlerden gelen veriler değerlendirilebilir. $\mathrm{Bu}$ durum sistemin daha kararlı çalışmasını sağlayabilir.

Robotun kapalı bir alandaki açıklıktan çıkma süresini elde etmek için bir takım testler gerçekleştirilmiştir. Bunun için 2 farklı kapalı test alanı oluşturulmuştur. Bu kapalı test alanları şekil 7 a ve b'de gösterilmektedir.
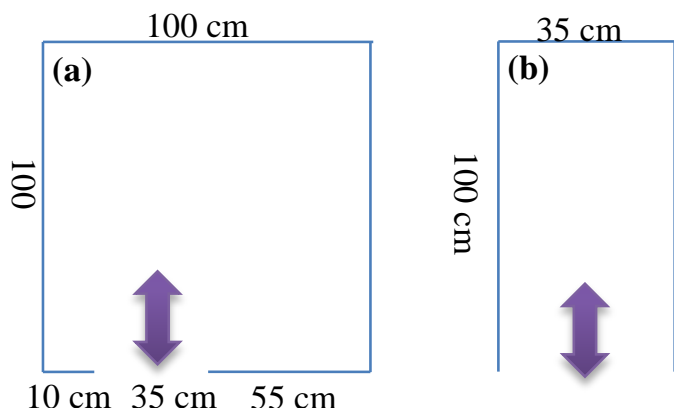

Şekil 7. (a) Test alanı-1 $\quad$ (b) Test alanı-2 ((a) Test field-1 (b) Test field-2)

Şekil 7.a'da gösterilen test alanı-1'de 35 cm'lik bir açıklık vardır. Robottan beklenen bu açıklığg tespit ederek 
çıkmasıdır. Test alanı-1'de elde edilen test verileri tablo 1 'de gösterilmektedir. $\mathrm{Bu}$ verilere göre robot, ortalama 85.8 saniye gibi bir sürede test alanı-1'deki açıklığı tespit ederek çıkışı bulabilmektedir. Yapılan literatür taramasına göre, yapılan çalışmalarda bu tür veriler paylaşılmadığından dolayı bir karşılaştırma yapmak mümkün değildir. Ancak bu çıkış süresi yeterlidir.

Tablo 1. Test alanı-1 için çıkış süreleri (Exit times for test field-1)

\begin{tabular}{|c|c|}
\hline Test No & Çıkıs Süresi (saniye) \\
\hline 1 & 120 \\
\hline 2 & 90 \\
\hline 3 & 132 \\
\hline 4 & 150 \\
\hline 5 & 120 \\
\hline 6 & 60 \\
\hline 7 & 90 \\
\hline 8 & 30 \\
\hline 9 & 36 \\
\hline 10 & 30 \\
\hline
\end{tabular}

Şekil 7.b'de gösterilen test alanı-2'de yine 35 cm'lik bir açıklık vardır. Ancak bu alan daha dar ve çıkıntısı olmayan düz bir alandır. Test alanı-2'de elde edilen test verileri tablo 2'de gösterilmektedir. $\mathrm{Bu}$ verilere göre robot, ortalama 10.3 saniye gibi kısa bir sürede test alan12'deki açıklığı tespit ederek çıkışı bulabilmektedir. Test alanı-2, daha dar olduğundan dolayı ön mesafe sensöründen gelen veriler çok küçük olmaktadır. Dolayısıyla bu veriler gözardı edilerek sadece arka mesafe sensöründen gelen veriler değerlendirmeye alınmaktadır. Böylece robot bir denemede tam tur geriye dönerek çıkışı bulabilmektedir.

Tablo 2. Test alanı-2 için çıkıș süreleri (Exit times for test field-2)

\begin{tabular}{|c|c|}
\hline Test No & Çıkış Süresi (saniye) \\
\hline 1 & 8 \\
\hline 2 & 10 \\
\hline 3 & 12 \\
\hline 4 & 8 \\
\hline 5 & 10 \\
\hline 6 & 12 \\
\hline 7 & 9 \\
\hline 8 & 12 \\
\hline 9 & 10 \\
\hline 10 & 12 \\
\hline
\end{tabular}

İkinci değerlendirme ise robotun sicaklık, nem ve gaz ölçümlerini yaparak wifi üzerinden göndermesi üzerine yapılabilir. $\mathrm{Bu}$ açıdan bakıldığında robot sensörlerden aldığı bilgileri istenen zaman aralığında başarılı bir şekilde web modülüne gönderebilmektedir. Buradaki en büyük zorluklardan biri modülün bazen gönderme işlemini gerçekleştirmemesidir. Gönderme işlemi çok s1k (10-20 saniyede bir) tekrar edilirse 3-4 seferde bir gönderme işlemi başarısızlıkla sonuçlanabilmektedir. Ama bu süre 1 dakika veya daha fazla aralıklarla tekrar edilirse sorun çıkmamaktadır. Bunun dışında wifi modülü ilk kullanımda bir defaya mahsus olmak üzere mutlaka güncellenmelidir. $\mathrm{Bu}$ çalışmada ESP8266 wifi modülü kullanılmadan önce wifi shield kullanılmıştır. Ancak bu shield motor sürücü ile pin çakışmasına sebep olmuştur. $\mathrm{Bu}$ pin çakışması nedeniyle robot wifi üzerinden veri gönderilmesi esnasında kendi etrafında dönmüştür. $\mathrm{Bu}$ nedenle ESP8266 modülü tercih edilmiştir.

\section{SONUC (CONCLUSION)}

$\mathrm{Bu}$ çalışmada insanın giremeyeceği yerlerdeki gaz, sıcaklık ve nem ölçümlerini gerçekleştiren, bu ölçümleri web sayfasına ileten, engelleri tespit ederek engellere çarpmayan, bir yerde kapalı kalırsa ve uygun bir açıklık varsa o açıklığı tespit ederek çıkış yolunu bulabilen çok sensörlü ve düşük maliyetli bir gezgin hizmet robotu geliştirilmiştir. Robot, yapılan uygulama ve testler sonucunda kapalı bir alandan hızlı ve başarılı şekilde çıkmıştır. Ayrıca ortamın gaz, nem ve sıcaklık değerlerini algılayıp web modülüne başarılı şekilde aktarmıştır.

Robotun hareketli olması ve sürekli dolaşması farklı konumlardaki ölçümlerin sürekli güncellenmesini sağlamakta ve insanların ulaşmakta zorluk çektikleri dar alanlara ulaşabilmektedir. $\mathrm{Bu}$ özellikler sabit ölçüm cihazlarına göre bir avantaj sağlamaktadır. Ayrıca gezgin robotun üzerine amaca uygun çok sayıda sensörlerin yerleştirilme imkanın olması ve elde edilen verilerin wifi üzerinden web modülüne aktarılması önemli bir avantaj olarak görülmektedir.

Gezgin robot ile insan ve canlılar için sakıncalı ve tehlikeli yerlere ulaşılarak veriler elde edilebilir. Gaz zehirlenmelerinin, aşırı sıcaklık durumlarının ve istenmeyen nemin önüne geçilebilir.

\section{6. ÖNERILLER (RECOMMENDATIONS)}

Geliştirilen robotun her ortamda rahat bir şekilde gezinebilmesi için mekanik aksam örümcek robot şeklinde tekrar düzenlenebilir. Robot bir ortamda kendi, kendine dolaşabileceği gibi kullanıcı tarafından web üzerinden manuel olarak kontrol edilebilir. Bunun için robota bir kamera entegre edilebilir. Ayrıca robot üzerine karbon monoksit, lpg-propan, hidrojen, hava kalite sensörü gibi sensörler eklenerek ölçüm sayısı artırılabilir. Bunun dişında GPS modülü eklenerek her yeri eşit oranda gezmesi sağlanabilir. Wifi olmayan yerler için bluetooth modülü eklenerek bluetooth üzerinden veri alış-verişi sağlanabilir.

Not: Hazırlanan çalışma, “Arduino Kullanarak Çeşitli Kategorilerde Elektronik Araç Geliştirilmesi ve Değerlendirilmesi” isimli 01/2015-8 no'lu-KÜBAP projesi tarafindan desteklenmiştir. Bu kapsamda, vermiş olduklarl maddi ve manevi katkılarından dolayı Kastamonu Üniversitesine teşekkür ederim.

Not: Bu çalışma 10-12 Nisan 2017 tarihlerinde Taşköprü'de düzenlenen "Uluslararası Taşköprü Pompeiopolis Bilim Kültür Sanat Araştırmaları Sempozyumunda” sözlü bildiri olarak sunulmuştur. 


\section{KAYNAKLAR (REFERENCES)}

[1] H-S. Juang, K-Y. Lum, "Design and Control of a Two-Wheel Self-Balancing Robot using the Arduino Microcontroller Board", 10th IEEE International Conference on Control and Automation (ICCA) Hangzhou, China, June 12-14, 634-639, 2013.

[2] W. M. Kadir, R.E. Samin , B.S. Ibrahim, "Internet controlled robotic arm.", Proc Eng, 41, 1065-1071, 2012.

[3] D. Özdemir, C. Köse, "Gezgin robotların çiftliklerde ürün yeri belirleme ve taşıma işlemlerinde kullanımı”, EÜFBED - Fen Bilimleri Enstitüsü Dergisi,1(1), 49-60, 2008.

[4] J.Sarik, I. Kymissis, "Lab kits using the Arduino prototyping platform", in IEEE Frontiers in Education Conference, Washington, 1-5, October $27-30,2010$.

[5] H. Dalkılıç, M. H. Özcanhan, "Gömülü Sistem Tabanlı Model Mobil Aracın Akıllı Telefonla Uzaktan Kontrolu", XVIII. Akademik Bilişim Konferansı -- AB 2016, 30 Ocak-5 Şubat, Aydın, 2016.

[6] O. Güngör, "Kaçak Elektrik Kullanımının GSM Aracılığıyla Takibi”, T, 4(8), 29-33, 2015.

[7] A. J. Lubbe, P. Kluge, "Development and Testing of a Wireless Controlled Car Using the Internet as Communication Medium", South African Journal of Industrial Engineering, 19(1), 137-147, 2008.

[8] A. M. Thomas, J. Joseph, R. Mathew, "Mobile Application for Automobile Management System", Journal for Research, 2(2), 6668, 2016.

[9] A. Sinha, P.Agarwal, M. Saini, "Design And Development Of A Vehicle Theft Security System Based On Arduino Microcontroller", Emerging trends in Engineering \& Management for Sustainable Development 2016 International conference, India, Şubat, 2016.

[10] D.Vaishnavi, E. Sundari, T.V. Sangeetha, S. Shrinidhi, P. Saravanan, "Design and Development of Computational
Intelligence for Enhanced Adaptive Cruise Control Using Arduino", Applied Mechanics and Materials, 852, 782-787, 2016.

[11] O. İ.Yavuz, A. Çetin, Ö. Eyecioğlu, “İki Tekerlekli Kendini Dengeleyen Robot", EEB 2016 Elektrik-Elektronik ve Bilgisayar Sempozyumu, Tokat TÜRKIYY, 11-13 Mayıs 2016

[12] S.Yalman, , A. Haşıloğlu, , "Hastanelerde Eş-Zamanlı İlaç Dağıtımı Yapan Hemșire /Hemșir Robotun Geliștirilmesi”, Tıp teknolojileri ulusal kongresi, Bodrum, Muğla, 15-18 Ekim 2015.

[13] N.Ya'acob , S. F. S Adnan, A. L. Yusof, A. E. Azhar, N. F. Naim, N. M. Nur, A. Mahmon, "RFID lab management system using Arduino microcontroller approach associate with webpage", Journal of Scientific Research and Development, 3 (2), 92-97, 2016.

[14] S. Kim, H. B. Kim, "High Resolution Mobile Robot Obstacle Detection Using Low Directivity Ultrasonic Sensor Ring", Advanced Intelligent Computing Theories and Applications. With Aspects of Artificial Intelligence: 6th International Conference on Intelligent Computing, ICIC 2010, Changsha, China, August 18-21, 2010 .

[15] A. Djajadi, M.Wijanarko, "Ambient Environmental Quality Monitoring Using IoT Sensor Network", Internetworking Indonesia Journal, 8(1), 41-47, 2016.

[16] D. Jalamkar, A.A. Selvakumar, "Use of Internet of Things in a Humanoid Robot - A Review", Advances in Robotics \& Automation, 5(2), 2016.

[17] M. Sevil, N. Elalmıș, H. Görgün, N. Aydın, "Akıllı Ev Sistemleri İçin Bulanık Mantık İle Klima Kontrolü Tasarımı", Sigma Mühendislik ve Fen Bilimleri Dergisi, 33 (3), 439-463, 2015.

[18] Internet: https://youtu.be/rMy9RqPCQg0, 04.08.2017

[19] Internet: https://youtu.be/ymAGacktKCM, 04.08.2017

[20] Internet: https://www.youtube.com/watch?v=NYqzc5SguO4, 04.08.2017. 